\title{
Chinese University EFL Learners' Foreign Language Writing Anxiety: Pattern, Effect and Causes
}

\author{
Meihua Liu ${ }^{1} \&$ Huiliuqian $\mathrm{Ni}^{2}$ \\ ${ }^{1}$ Department of Foreign Languages and Literatures, Tsinghua University, China \\ ${ }^{2}$ School of Journalism \& Communication, Tsinghua University, China \\ Correspondence: Meihua Liu, Department of Foreign Languages and Literatures, Tsinghua University, China. \\ E-mail: ellenlmh@yahoo.com
}

\author{
Received: November 5, 2014 Accepted: December 15, 2014 Online Published: February 13, 2015 \\ doi:10.5539/elt.v8n3p46 URL: http://dx.doi.org/10.5539/elt.v8n3p46
}

\begin{abstract}
This paper reports on the result of a study on Chinese university EFL learners' foreign language writing anxiety in terms of general pattern, effect and causes. 1174 first-year students answered the 26-item Foreign Language Writing Anxiety Scale (FLWAS) (Young, 1999) and took an English writing test, 18 of whom were invited for semi-structured interviews. The results showed that 1) FLWAS had three principal components-low confidence in English writing (FLWAS1), dislike of English writing (FLWAS2) and English writing apprehension evaluation (FLWAS3), 2) the whole sample, as well as male and female students, were generally confident in and liked English writing, and were not apprehensive of having their English writing evaluated, 3) significant differences existed between male and females students, and among different proficiency groups in all the FLWAS scales, 4) foreign language writing anxiety significantly negatively affected students' performance in the English writing test, and 5) a number of factors contributed to the students' foreign language writing anxiety.
\end{abstract}

Keywords: writing anxiety, pattern, effect, cause

\section{Introduction}

Foreign language (FL) anxiety, an important affective factor, has been the focus of an array of research, which finds that that it often debilitates the learning of a SL/FL (Aida, 1994; Ewald, 2007; Horwitz, 2000, 2001; Hurd \& Xiao, 2010; Liu, 2006, 2009; Mills, Pajares, \& Herron, 2006; Tallon, 2009; Woodrow, 2006, 2011). Though it is generally agreed that FL anxiety exists in various aspects of second/foreign language (SL/FL) learning such as listening, reading, speaking and writing (Kinoshita \& Bowman, 1998; Liu \& Hu, 2009; Sellers, 2000; Vogely, 1998), only speaking anxiety has been predominantly researched (Chen, 2002; Dewaele \& Tsui, 2013; Ewald, 2007; Horwitz, 2000, 2001; Hurd \& Xiao, 2010; Liu, 2006, 2009; Shao, Ji, \& Yu, 2013; Tallon, 2009), while anxiety concerned with reading, listening and writing has not been adequately investigated. As English writing has become increasingly important in Chinese universities in recent years, the present study aimed to investigate foreign language writing anxiety in terms of pattern, effect and causes in Chinese university EFL learners.

\section{Literature Review}

\subsection{Foreign Language Anxiety}

Anxiety, the subjective feeling of tension, apprehension, nervousness, and worry associated with an arousal of the automatic nervous system (Spielberger, 1972), has long been a focus of research in various fields such as stage performance and the learning of a certain subject (Barrat, 1972; Rachman, 1998; Speilberger, 1972). Likewise, foreign language (FL) anxiety, which has proved as a phenomenon related to but distinguishable from other types of anxiety such as singing and dancing anxieties (Horwitz, 2001), has aroused great interest among scholars of SL/FL learning since 1970s. It is commonly believed that FL anxiety prevails in SL/FL learners (E. Horwitz, M. Horwitz, \& Cope, 1986; MacIntyre \& Gardner, 1989).

Horwitz, one of the earliest and most prestigious investigators in the area, formed a general picture of FL classroom anxiety, as classroom serves as a typical environment of formal instruction and is thus particularly stressful (Horwitz, 2000, 2001; Horwitz et al., 1986; Matsuda \& Gobel, 2004). According to Horwitz and her colleagues (1986), communication apprehension, test anxiety and fear of negative evaluation were three components of FL anxiety. Based on this definition, they (1986) developed the Foreign Language Classroom 
Anxiety Scale (FLCAS), a 33-item five point Likert scale, to measure students' FL anxiety levels. Horwitz (1986) further examined the construct validity of the FLCAS and its correlation with other specific anxieties. Since then, both the definition and the scale have been widely accepted and applied in empirical research in a multitude of SL/FL contexts (Aida, 1994; Chen, 2002; Cheng, Horwitz, \& Schallert, 1999; Dewaele \& Thirtle, 2009; Dewaele \& Tsui, 2013; Ewald, 2007; Horwitz, 2000, 2001; Hurd \& Xiao, 2010; Liu, 2006, 2009; Marcos-Llinás \& Garau, 2009; Mills et al., 2006; Tallon, 2009; Shao et al., 2013). These studies have predominantly found that FL anxiety and SL/FL performance are negatively correlated and that anxiety may lead to deficiency in SL/FL learning and performance. For example, Coulombe (2000) found a smaller but significant negative correlation between FLCAS scores and final grades in eleven French classes. Liu and Jackson (2008) administered a 70-item survey to 547 Chinese first-year undergraduate non-English majors and found that that the students' unwillingness to communicate and foreign language anxiety were significantly correlated with their self-rated English proficiency and access to English.

Meanwhile, as more research on FL anxiety has been done, more researchers come to realize that FL anxiety often interacts with a multitude of other variables during the complex process of SL/FL learning, which has resulted in numerous studies on the interaction of FL anxiety and other variables in SL/FL learning such as age, gender, year of study, motivation and strategy use (Chu, 2008; Dewaele \& MacIntyre, 2014; Gregersen, Meza, \& MacIntyre, 2014; Liu, 2006, 2009; Lu \& Liu, 2011; Pichette, 2009; Shao et al., 2013). For example, Chu (2008) examined the interrelationship among shyness, L2 learning strategy use, L2 learning motivation, foreign language anxiety, and willingness to communicate. 364 university students answered a battery of questionnaires, the results of which showed that students who reported experiencing more FL anxiety in their English class showed less willingness to communicate in both Chinese and English. Dewaele and MacIntyre (2014) investigated Foreign Language Enjoyment (FLE) and Foreign Language Classroom Anxiety (FLCA) in class. 1746 FL learners from around the world answered the 21-item FLE and the 8-item FLCAS. The results showed that levels of FLE were significantly higher than those of FLCA and that FLE and FLCA were linked to a number of independent variables: participants' perception of their relative level of proficiency within the FL classroom, number of languages known, education level, number of FLs under study, age and general level of the FL. The study also found that female participants reported both more FLE and more FLCA and that participants' cultural background had a significant effect on their scores.

\subsection{Foreign Language Writing Anxiety}

As more scholars become interested in FL anxiety, they come to realize that anxiety actually exists in almost all aspects of SL/FL learning (Kim, 2000; Leki, 1999; Vogely, 1998; Woodrow, 2006). As a type of anxiety specifically associated with SL/FL writing, FL writing anxiety has long been neglected since writing is often the least practiced and thus considered the least important of the four skills of a SL/FL. Nevertheless, as English writing has become increasingly more important in recent decades, FL writing anxiety has captured the interest of more and more researchers. Based on the Daly-Miller Writing Apprehension Test (WAT) (Daly \& Miller, 1975) which was initially developed to assess first language writing anxiety, the 26-item Foreign Language Writing Anxiety Scale (FLWAS) was developed (cited in Young, 1999) and has been generally used to measure S/FL writing anxiety (Cheng et al., 1999; Gungle \& Talor, 1989; Lu, 2005).

Kean, Gylnn, and Britton (1987) found that when there was a time pressure, writing anxiety was more likely to create a negative effect on the quality of students' work, which confirmed the result of an earlier study (Faigley, Daly, \& Witte, 1981). Cheng (2002) studied the relationships among students' perceptions of their FL writing anxiety and various learner differences. Regression analysis results indicated that perceived FL writing competence better predicted FL writing anxiety than FL writing achievement did. Female students in the study reported to have higher level of writing anxiety than male students, while no significant difference in writing anxiety was found among freshmen, sophomores and juniors. Based on FLWAS, Cheng (2004) developed a multidimensional Second Language Writing Anxiety Inventory (SLWAI), which consisted of somatic anxiety, cognitive anxiety and avoidance behavior. SLWAT, together with FLCAS, was used in Cheng et al. (1999) to differentiate the components of general FL anxiety and FL writing anxiety. The findings suggested that FL writing anxiety was a language-skill-specific anxiety, while FL classroom anxiety was a more general type of anxiety about learning a FL in formal educational contexts. The study also revealed three important components of SLWAT: Low Confidence in Writing English, Aversiveness of Writing in English, and English Writing Evaluation Apprehension, among which low self-confidence was found to be an important component of both FLCAS and SLWAT constructs.

Yan and Wang (2014) investigated the impacts of FL writing anxiety in a Chinese-to-English translation class of 50 translation major students in Hong Kong. Significant correlations were found between FL writing anxiety, 
translation performance, and language ability. They also found that the fear of being evaluated and the general apprehension of writing in English contributed significantly to predicting success in the translation class. In Woodrow's (2011) study, a total of 738 students in China answered questionnaires related to self-efficacy and anxiety in writing English and finished a writing task immediately thereafter. The study revealed that both anxiety and self-efficacy predicted writing performance, while self-efficacy mediated the relationship between writing performance and FL writing anxiety.

As discussed above, though FL anxiety has been a concern of numerous studies, FL writing anxiety has not been adequately researched. As an important part of SL/FL language learning, FL writing anxiety deserves more research to help learners to write better in a SL/FL. Situated in Chinese undergraduate EFL contexts, the present research aimed to explore FL writing anxiety in Chinese learners in terms of pattern, effect and causes. To achieve this aim, the following research questions were formulated:

1) What are the components of the FL writing anxiety scale?

2) What are the profiles of the students' FL writing anxiety when dealing with a writing task?

3) How is the students' FL writing anxiety related to their English writing performance?

4) What are the causes for the students FL writing anxiety and what are their coping strategies?

\section{The Present Study}

\subsection{Participants}

The participants of the present study consisted of 1174 (494 males and 680 females) first-year students from three universities in China. With an average age of 18.56 and an age range of 14 to 22, the students were from various disciplines such as electronic engineering, business and administration, chemistry, architecture and mathematics.

Among these survey respondents, 18 (10 males and 8 females) were randomly chosen for semi-structured interviews. Of them, 13 started to learn English in primary school and 5 in secondary school; 5 started to learn English writing in primary school and 13 in secondary school. Before coming to university, they usually wrote English essays of 20-100 words, once a week or a month, mainly for the purpose of reinforcing their knowledge of grammar. Even when they were trained on how to write essays in English, the training was enormously oriented for exams which often asked them to translate an imagined scenario into English of 100 words. After coming to university, 14 took a formal English writing course and were required to write 2-3 English essays of around 400 words per se for the course, the other 4 did not take any English writing course, but did practice writing for College English Test bands 4 and 6 (nation-wide English proficiency and exit tests for undergraduate and postgraduate non-English majors respectively).

\subsection{Instruments}

The data of the present study was gathered via questionnaires, interviews and an English writing test, as detailed below.

Foreign Language Writing Anxiety Scale. With a reliability score of .883 in the present study, the 26-item Foreign Language Writing Anxiety Scale (FLWAS) was adapted from that in Young (1999). To better fit the present context, the words "foreign language" were changed into "English" in all items. Each item was placed on a 5-point Likert scale, with five alternatives ranging from "Strongly disagree" to "Strongly agree" with values of 1-5 assigned to the descriptors respectively.

Semi-structured interview. In order to acquire the insider view of foreign language writing anxiety, 18 survey respondents were invited for semi-structured interviews, which covered such questions as past English writing experiences, feelings when writing in English, reasons for anxiety when writing in English, and coping strategies.

The background questionnaire. The background questionnaire aimed to collect personal information such as gender, age, university, and year of study.

English writing test. The English writing test required students to write an argumentative essay of 250-300 words in 30 minutes on a TOEFL topic "Do you agree or disagree with the following statement? People are never satisfied with what they have; they always want something more or something different. Use specific reasons to support your answer". An argumentative essay was required because this genre was the most commonly used in university, and the topic was chosen because it was general and thus suitable to everyone regardless of year of study, gender, or discipline. 


\subsection{Procedure}

Thirty-nine intact classes from four universities in China answered the survey in 10 minutes in class, and then took the English writing test in 30 minutes in the $14^{\text {th }}$ week of the usually 18 -week semester. After that, 18 students were randomly chosen for a semi-structured interview, each of which lasted 10-15 minutes. Both the survey and interview were conducted in Chinese for better understanding and expression.

\subsection{Data Analysis}

Rotated principal factor analyses were run to identify the underlying factors of FLWAS. Statistical analyses were conducted on FLWAS in terms of frequency, percentage, mean and standard deviation to determine the extent to which the respondents felt anxious when writing in English. Independent samples t-tests and ANOVA were then run to explore the differences in FLWAS between male and female students and among students of varying English writing proficiency groups, respectively. And correlational and regressional analyses were conducted to examine the effect of FLWAS on students' English writing performance.

All the interviews were transcribed, double checked, and then subjected to thematic content analyses (Peterson, Engle, Kenney, Kreutzer, Nolting, \& Ogden, 2007). The results were integrated into the discussion of survey results. And pseudo names were used when presenting the interview data results.

\section{Results}

\subsection{Factor Analyses of the FLWAS}

In order to reveal the underlying components of FLWAS, a confirmatory three-factor analysis with varimax rotation for FLWAS was conducted, as done in Cheng et al. (1999). As shown in Table 1, the three factors were: Low Self-Confidence in Writing English (FLWAS1) which included 9 items reflective of low self-confidence in English, Dislike of Writing English (FLWAS2) which had 8 items indicative of negative attitudes or dislike of writing English, and English Writing Evaluation Apprehension (FLWAS3) which covered 6 items suggestive of fear of actual or potential evaluation of their English writing. These three factors accounted for $23.66 \%, 22.35 \%$ and $15.27 \%$ of the total variance respectively.

Table 1. Varimax rotated loadings for factor analysis of FLWAS $(\mathrm{N}=1174)$

\begin{tabular}{llll}
\hline & 1 & 2 & 3 \\
\hline 1) I avoid writing in English. & .173 &. $\mathbf{2 0 3}$ & .562 \\
2) I have no fear of my English writing being evaluated. & .085 & .259 & $\mathbf{. 3 1 4}$ \\
3) I look forward to writing down my ideas in English. & -.047 & $\mathbf{. 5 4 8}$ & .279 \\
4) I am afraid of writing essays in English when I know they will be evaluated. & .175 & .076 & $\mathbf{. 6 5 9}$ \\
5) Taking an English composition course is a very frightening experience. & .088 & .179 & .658 \\
6) Handing in an English composition course is a very frightening experience. & -.109 & -.131 & -.725 \\
7) My mind seems to go blank when I start to work on an English composition. & .277 & .056 & .589 \\
8) Expressing ideas through writing in English seems to be a waste of time. & -.205 & $\mathbf{. 2 6 8}$ & .640 \\
9) I would enjoy submitting my English writing to magazines for evaluation and & .371 & .425 & $\mathbf{- . 3 1 4}$ \\
publication. & & & \\
10) I like to write my ideas down in English. & .088 & $\mathbf{. 6 5 4}$ & .210 \\
11) I feel confident in my ability to clearly express my ideas in English writing. & $\mathbf{. 4 2 0}$ & .416 & .205 \\
12) I like to have my friends read what I have written in English. & .408 & .535 & $\mathbf{- . 3 2 9}$ \\
13) I'm nervous about writing in English. & $\mathbf{. 3 5 1}$ & .155 & .550 \\
14) People seem to enjoy what I write in English. & $\mathbf{. 3 9 9}$ & .515 & -.063 \\
15) I enjoy writing in English. & .189 & $\mathbf{. 7 1 0}$ & .155 \\
16) I never seem to enjoy what I write in English. & .131 & $\mathbf{. 2 6 6}$ & .459 \\
17) Writing in English is a lot of fun. & .085 & $\mathbf{. 6 9 4}$ & .211 \\
18) I expect to do poorly in English composition classes even before I enter them. & $\mathbf{. 3 2 4}$ & .137 & .567 \\
\hline
\end{tabular}


19) I like seeing my thoughts on paper in English.

20) Discussing my English writing with others is an enjoyable experience.

21) I have a terrible time organizing my ideas in an English composition course.

22) When I hand in an English composition, I know I'm going to do poorly.

23) It's easy for me to write good English compositions.

24) I don't think I write in English as well as most other people.

25) I don't like my English compositions to be evaluated.

26) I'm no good at writing in English.

$\begin{array}{lll}-.029 & .729 & .253 \\ .236 & .591 & . \mathbf{2 2 5} \\ \mathbf{. 5 8 4} & .013 & .385 \\ \mathbf{. 4 7 9} & .104 & .525 \\ \mathbf{. 5 3 0} & .328 & .147 \\ \mathbf{. 5 7 4} & .029 & .339 \\ .248 & .116 & . \mathbf{4 8 0} \\ \mathbf{. 6 1 2} & .232 & .325\end{array}$

As shown in Table 1, all the items within a subcomponent were generally highly correlated with that subcomponent: the loadings were .324 to .612 for FLWASS1, 203 to .729 for FLWASS2, and to -.329 to .659 for FLWASS3 respectively.

In addition, the three subscales of FLWAS were all highly positively correlated with one another as well as FLWAS, with a coefficient range of .613 to $.886(\mathrm{p} \leq .01)$ (Table 2$)$.

Table 2. Correlations among the FLWAS components

\begin{tabular}{lllll}
\hline & FLWAS1 & FLWAS2 & FLWAS3 & FLWAS \\
\hline FLWAS1 & 1 & $.622^{* *}$ & $.626^{* *}$ & $.886^{* *}$ \\
FLWAS2 & & 1 & $.613^{* *}$ & $.865^{* *}$ \\
FLWAS3 & & & 1 & $.824^{* *}$ \\
FLWAS & & & & 1 \\
\hline
\end{tabular}

Notes: $* *=p \leq .01$

\subsection{Profiles of English Writing Anxiety}

\subsubsection{Analyses of the FLWAS Items}

In order to examine the general profiles of the students' foreign language writing anxiety, we computed the frequency (the first number) and percentage (the second number) of each FLWAS item (Table 3).

Table 3. FLWAS items with numbers and percentages of students selecting each alternative $(\mathrm{N}=1174)$

\begin{tabular}{|c|c|c|c|c|}
\hline SD & $\mathrm{D}$ & $\mathrm{N}$ & A & SA \\
\hline \multicolumn{5}{|c|}{ 1) I avoid writing in English. } \\
\hline $136 / 11.6 \%$ & $541 / 46.1 \%$ & $188 / 16 \%$ & $257 / 21.9 \%$ & $52 / 4.4 \%$ \\
\hline \multicolumn{5}{|c|}{ 2) I have no fear of my English writing being evaluated. } \\
\hline $62 / 5.3 \%$ & $272 / 23.2 \%$ & $194 / 16.5 \%$ & $520 / 44.3 \%$ & $126 / 10.7 \%$ \\
\hline \multicolumn{5}{|c|}{ 3) I look forward to writing down my ideas in English. } \\
\hline $56 / 4.8 \%$ & $306 / 26.1 \%$ & $233 / 19.8 \%$ & $435 / 37.1 \%$ & $144 / 12.3 \%$ \\
\hline \multicolumn{5}{|c|}{ 4) I am afraid of writing essays in English when I know they will be evaluated. } \\
\hline $153 / 13 \%$ & $576 / 49.1 \%$ & $200 / 17 \%$ & $209 / 17.8 \%$ & $36 / 3.1 \%$ \\
\hline \multicolumn{5}{|c|}{ 5) Taking an English composition course is a very frightening experience. } \\
\hline $163 / 13.9 \%$ & $466 / 39.7 \%$ & $332 / 28.3 \%$ & $175 / 14.9 \%$ & $38 / 3.2 \%$ \\
\hline \multicolumn{5}{|c|}{ 6) Handing in an English composition course is a very frightening experience. } \\
\hline $148 / 12.6 \%$ & $534 / 45.5 \%$ & $269 / 22.9 \%$ & $167 / 14.2 \%$ & $56 / 4.8 \%$ \\
\hline
\end{tabular}




\begin{tabular}{lllll}
\hline $143 / 12.2 \%$ & $571 / 48.6 \%$ & $189 / 16.1 \%$ & $232 / 19.8 \%$ & $39 / 3.3 \%$
\end{tabular}

8) Expressing ideas through writing in English seems to be a waste of time.
$253 / 21.6 \%$
$639 / 54.4 \%$
$143 / 12.2 \%$
$105 / 8.9 \%$
$34 / 2.9 \%$

9) I would enjoy submitting my English writing to magazines for evaluation and publication.
$141 / 12 \%$
$495 / 42.2 \%$
$276 / 23.5 \%$
$203 / 17.3 \%$
$59 / 5 \%$

10) I like to write my ideas down in English.
$61 / 5.2 \%$
$265 / 22.6 \%$
$225 / 19.2 \%$
$485 / 41.3 \%$
$138 / 11.8 \%$

11) I feel confident in my ability to clearly express my ideas in English writing.
$57 / 4.9 \%$
$322 / 27.4 \%$
$260 / 22.1 \%$
$425 / 36.2 \%$
$110 / 9.4 \%$

12) I like to have my friends read what I have written in English.

$92 / 7.8 \%$

$482 / 41.1 \%$

$231 / 19.7 \%$

$293 / 25 \%$

$76 / 6.5 \%$

13) I'm nervous about English writing.

$115 / 9.8 \% \quad 565 / 48.1 \% \quad 224 / 19.1 \% \quad 33 / 2.8 \%$

14) People seem to enjoy what I write in English.

\begin{tabular}{|c|c|}
\hline $61 / 5.2 \%$ & $300 / 25.6 \%$ \\
\hline
\end{tabular}

15) I enjoy writing in English.

$\begin{array}{lllll}59 / 5 \% & 380 / 32.4 \% & 288 / 24.5 \% & 345 / 29.4 \% & 102 / 8.7 \%\end{array}$

16) I never seem to enjoy what I write in English.
$232 / 19.8 \%$
$569 / 48.5 \%$
$194 / 16.5 \%$
$150 / 12.8 \%$
$29 / 2.5 \%$

17) Writing in English is a lot of fun.
$55 / 4.7 \%$
$253 / 21.6 \%$
$300 / 25.6 \%$
$452 / 38.5 \%$
$114 / 9.7 \%$

18) I expect to do poorly in English composition classes even before I enter them.
$196 / 16.7 \%$
$534 / 45.5 \%$
$265 / 22.6 \%$
$142 / 12.1 \%$
$37 / 3.2 \%$

19) I like seeing my thoughts on paper in English.

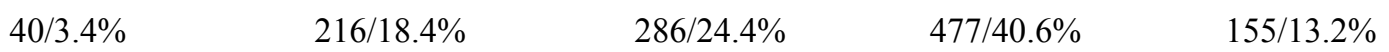

20) Discussing my English writing with others is an enjoyable experience.

$\begin{array}{lllll}64 / 5.5 \% & 326 / 27.8 \% & 338 / 28.8 \% & 341 / 29 \% & 105 / 8.9 \%\end{array}$

21) I have a terrible time organizing my ideas in an English composition course.
$134 / 11.4 \%$
$490 / 41.7 \%$
$237 / 20.2 \%$
$284 / 24.2 \%$
$29 / 2.5 \%$

22) When I hand in an English composition, I know I'm going to do poorly.
$128 / 10.9 \%$
$574 / 48.9 \%$
$266 / 22.7 \%$
$182 / 15.5 \%$
$24 / 2 \%$

23) It's easy for me to write good English compositions.
$55 / 4.7 \%$
$392 / 33.4 \%$
$391 / 33.3 \%$
$302 / 25.7 \%$
$34 / 2.9 \%$

24) I don't think I write in English as well as most other people.
$70 / 6 \%$
$444 / 37.8 \%$
$290 / 24.7 \%$
$335 / 28.5 \%$
$35 / 3 \%$

25) I don't like my English compositions to be evaluated.
$95 / 8.1 \%$
$532 / 45.3 \%$
$254 / 21.6 \%$
$258 / 22 \%$
$35 / 3 \%$

26) I'm no good at writing in English.

$78 / 6.6 \%$

$381 / 32.5 \%$

$306 / 26.1 \%$

$334 / 28.4 \%$

$75 / 6.4 \%$

Notes: $\mathrm{SD}=$ Strong disagree; $\mathrm{D}=$ Disagree; $\mathrm{N}=$ Neither disagree or agree; $\mathrm{A}=$ Agree; $\mathrm{SA}=$ Strongly agree. 
As shown in Table 3, in terms of FLWAS1 items, $46.6 \%$ of the participants (strongly) agreed that they were confident in their ability to clearly express their ideas in English writing (item 11), 23\% (strongly) endorsed that they were nervous about English writing (item 13), 19.9\% (strongly) believed that people seemed to enjoy what they wrote in English (item 14), 15.3\% (strongly) claimed that they expected to do poorly in English composition classes even before entering them (item 18), 26.7\%, 17.5\%, 28.6\% 31.5\% and $34.8 \%$ of them (strongly) agreed with items 21 (having a terrible time organizing ideas in English composition courses), 22 (doing poorly in an English composition), 23 (being easy to write good English compositions), 24 (Writing in English not as well as most other people) and 26 (being not good at English writing), respectively. These findings clearly indicate that the participants were generally confident in English writing.

In regard to FLWAS2 items, $26.3 \%, 49.4 \%, 11.8 \%, 53.1 \%, 28.1 \%, 15.3 \%, 48.2 \%$, and $53.8 \%$ of the respondents (strongly) endorsed items 1 (avoiding English writing), 3 (looking forward to writing down ideas in English), 8 (being a waste of time to express ideas in English writing), 10 (liking to write ideas down in English), 15 (enjoying English writing), 16 (never enjoying what they wrote in English), item 17 (English writing being a lot of fun), and 19 (liking seeing their thoughts in English), respectively. These findings demonstrate that more than half of the participants generally liked English writing, believing it was fun and beneficial.

With regard to FLWAS3 items, 55\%, 20.9\%, 22.3\%, 31.5\%, 37.9\%, and 25\% of the respondents (strongly) supported items 2 (having no fear of having their English writing being evaluated), 4 (being afraid of English writing if it was to be evaluated), 9 (enjoying submitting English writing to magazines for evaluation and publication), 12 (liking to have friends read what they had written in English), 20 (being enjoyable to discuss English writing with others), and 25 (not liking their English compositions to be evaluated), respectively. These findings suggest that more than half of the students generally were not afraid of actual or potential evaluation of their English writing and that they, on the contrary, liked to have their English writing read and evaluated.

\subsubsection{General Pattern}

In order to know the general pattern of the students' English writing anxiety, the mean and standard deviation of the FLWAS and its components were computed. As shown in Table 3, the participants scored 2.81 on FLWAS1, 2.65 on FLWAS2, 2.93 on FLWAS3 and 2.79 on FLWAS, all below the scale midpoint 3. This means that on general, more than half of the students were confident in (FLWAS1) and like (FLWAS2) English writing, were not afraid of having their English writing evaluated (FLWAS3), and were not anxious about English writing (FLWAS).

Meanwhile, the same pattern was observed for both male and female students, who also scored lower than the scale midpoint 3 on all the FLWAS scales, as noted in Table 3.

Table 4. Statistical analyses of the FLWAS scales $(\mathrm{N}=1174)$

\begin{tabular}{llllllllll}
\hline & \multicolumn{2}{l}{ Whole sample (1174) } & \multicolumn{2}{l}{ Male (494) } & \multicolumn{3}{l}{ Female (680) } & \multicolumn{3}{c}{ Results of $t$-test for gender } \\
\cline { 2 - 10 } & Mean & SD & Mean & SD & Mean & SD & t & p & Effect size \\
\hline FLWAS1 & 2.81 & .63 & 2.88 & .62 & 2.75 & .64 & 4.08 & .000 & \\
FLWAS2 & 2.65 & .67 & 2.76 & .64 & 2.55 & .68 & 6.59 & .000 & \\
FLWAS3 & 2.93 & .64 & 2.97 & .598 & 2.88 & .68 & 2.95 & .003 & \\
FLWAS & 2.79 & .52 & 2.86 & .49 & 2.73 & .53 & 5.31 & .000 &
\end{tabular}

Notes: FLWAS1 = Low Self-Confidence in English Writing; FLWAS2 = Dislike of English Writing; FLWAS = English Writing anxiety; FLWAS3 = English Writing Evaluation Apprehension

Table 4 also shows that male students scored higher on all the FLWAS scales than their female counterparts. And statistically significant differences were observed between them in all the FLWAS scales $(t=2.95-6.59, \mathrm{p} \leq .003)$, as proved by the independent samples t-test results presented in Table 3. This suggests that compared with their female counterparts, male students felt significantly more anxious about English writing (FLWAS), significantly less confident in English writing (FLWAS1), significantly more apprehensive of English writing evaluation (FLWAS3), and liked English writing significantly less (FLWAS2).

This finding was generally consistent with the interview report: among the 18 interviewees, 13 reported feeling anxious when writing in English due to various reasons, as detailed in the coming part of the paper. 


\subsubsection{Within-Group Pattern}

Analyses of the writing test scores revealed that the participants scored 5.0 to 13.5 in the writing test, with a mean of 9.35 and a standard deviation of 1.56. Based on the scores, the participants were classified into low-proficiency $(5.0 \leq$ scores $<7.79)$, intermediate-proficiency $(7.79 \leq$ scores $<10.91)$, and high-proficiency $(10.91 \leq$ scores $\leq 13.5)$ groups. $498(28.95 \%)$ of the participants fell in the low-proficiency group, 897 (52.7\%) were in the intermediate-proficiency group, and 307 (17.85\%) were in the high-proficiency group.

Results of the statistical analyses of the three proficiency groups' level of foreign language writing anxiety are summarized in Table 5. The results show that the students of the three groups, like the whole sample, scored below the scale midpoint 3 in all FLWAS scales, indicating that they were generally confident in and liked English writing, and were not apprehensive of English writing evaluation.

Table 5. Statistical analyses of the FLWAS scales across proficiency levels

\begin{tabular}{lllllll}
\hline & \multicolumn{2}{l}{$\begin{array}{l}\text { Low-proficiency } \\
(\mathrm{N}=712)\end{array}$} & $\begin{array}{l}\text { Intermediate-proficiency } \\
(\mathrm{N}=309)\end{array}$ & \multicolumn{2}{l}{$\begin{array}{l}\text { High-proficiency } \\
(\mathrm{N}=153)\end{array}$} \\
\cline { 2 - 7 } & Mean & $\mathrm{SD}$ & Mean & $\mathrm{SD}$ & Mean & $\mathrm{SD}$ \\
\hline FLWAS1 & 2.96 & .68 & 2.85 & .62 & 2.74 & .62 \\
FLWAS2 & 2.76 & .69 & 2.66 & .67 & 2.60 & .67 \\
FLWAS3 & 3.02 & .66 & 2.95 & .63 & 2.88 & .65 \\
FLWAS & 2.91 & .54 & 2.82 & .51 & 2.74 & .51 \\
\hline
\end{tabular}

Comparison of the scores across levels demonstrates that the low-proficiency students reported to be the least confident in English writing, dislike English writing the most, and the most apprehensive of having their English writing evaluated, the high-proficiency students reported to be the least in all aspects of foreign language writing anxiety, and the intermediate-proficiency group stood in between. And the one-way ANOVA analyses revealed that significant differences existed among the three groups in all FLWAS scales, with F values ranging from 6.74 (FLWAS2 \& FLWAS3) to 15.82 (FLWAS1) (Table 6). As noted in Table 6, the three groups differed significantly from one another in terms of confidence in English writing (FLWAS1) and overall English writing anxiety (FLWAS), the low-proficiency group differed from their group 2 and 3 peers in dislike of English writing (FLWAS2) and their group 3 counterparts in English writing evaluation apprehension (FLWAS3).

Table 6. ANOVA results of the FLWAS scales

\begin{tabular}{llllllll}
\hline & $\begin{array}{l}\text { Sum of } \\
\text { squares }\end{array}$ & df & $\begin{array}{l}\text { Mean } \\
\text { square }\end{array}$ & $\mathrm{F}$ & $\mathrm{p}$ & $\begin{array}{l}\text { Location of significant } \\
\text { differences }(\mathrm{p}=.05)\end{array}$ & $\begin{array}{l}\text { Effect size } \\
\left(\widehat{\omega}^{2}\right)\end{array}$ \\
\hline FLWAS1 & 12.52 & 2 & 6.26 & 15.82 & .000 & all & .007 \\
FLWAS2 & 6.097 & 2 & 3.05 & 6.74 & .001 & $1 \& 2,1 \& 3$ & .004 \\
FLWAS3 & 5.56 & 2 & 2.78 & 6.74 & .001 & $1 \& 3$ & .003 \\
FLWAS & 7.23 & 2 & 3.61 & 13.63 & .000 & all & .0041 \\
\hline
\end{tabular}

\subsection{Effect of Foreign Language Writing Anxiety on Writing Performance}

In order to examine the effect of foreign language writing anxiety on the students' performance in English writing, correlational and regression analyses were conducted, the results of which are presented in Tables 6 and 7 respectively.

Table 7. Correlations between FLWAS scales and English writing performance $(\mathrm{N}=1635)$

\begin{tabular}{lllll}
\hline & FLWAS1 & FLWAS2 & FLWAS3 & FLWAS \\
\hline English writing performance & $-.136^{* *}$ & $-.091^{* *}$ & $-.074^{* *}$ & $-.123^{* *}$ \\
\hline
\end{tabular}

Notes: $* *=\mathrm{p}<0.01$. 
Table 7 shows that all the FLWAS scales were significantly negatively correlated with students' performance in English writing $(r=-.136 \sim .091, \mathrm{p}<0.01)$. This indicates that the more diffident a student was in English writing, the more s/he disliked English writing, and/or the more apprehensive s/he was of English writing evaluation, the worse s/he performed in the English writing test.

Regression analyses further revealed that FLWAS1 was a powerful predictor of students' performance in English writing (Table 8$)(\beta=-.138, p=.000)$.

Table 8. Regression coefficients and significance

\begin{tabular}{lllll}
\hline Performance in English writing & $\beta$ & $t$ & $\mathrm{p}$ & VIF \\
\hline FLWAS1 & -.138 & -5.72 & .000 & 1.000 \\
\hline
\end{tabular}

This finding is further supported by the interviewees' reports. Among the 18 interviewees, 1 reported that he was not sure whether anxiety affected his English writing performance and 3 believed that anxiety had no effect on the latter. Among the other 14 interviewees, 6, 3 and 3 claimed that anxiety affected their English writing performance seriously, sometimes and slightly, respectively.

\subsection{Causes for Foreign Language Writing Anxiety}

Among the thirteen interviewees who reported feeling anxious when writing in English, five reported feeling the most anxious when analyzing the task requirement because of uncertainty; 3 recalled that they felt the most anxious upon beginning to write because it was often difficult for them to write out the first sentence; 2 thought outlining was the most anxiety-provoking because they could not find a clue; 1 became the most anxious when he could not find the most appropriate expression; and 1 was the most anxious when submitting her essay. The other 8 interviewees reported not feeling anxious when writing in English, 2 of whom confided that they even felt slightly excited and even proud, because "I never know that I have mastered so many words" (Shi, male, Electronic Engineering).

When asked about the causes for their English writing anxiety, the interviewees identified the followings: 1) It is difficult to write in English, 2) they desired to write out more proper expressions, 3) they cared (too) much about exam results, 4) they were limited in vocabulary, 5) they were lack of English writing practice, 6) they were not familiar with the required writing genre, and 7) they were slow in English writing. Six interviewees believed that genre could be a factor that provoked anxiety in them, stating that familiar genres could put them at ease while strange genres, especially academic papers, frustrated them and caused them to become anxious. Some interviewees claimed that their vocabulary became smaller because of their decreased practice in English writing, which caused them to become anxious when writing in English.

To cope with the anxiety, they adopted a number of strategies such as comforting themselves, revising the essay repeatedly, continuing to write despite the anxiety, reading other students' essays, and turning to dictionary. When not sure of the task requirement, they would re-analyze the topic and make a list of the main points. When not having a clue of what to write, they would try hard to brainstorm and outline, because "making an outline and then filling the content make writing easier" (Sun, female, Physics). When being unable to think of an appropriate expression, they would check dictionaries to find synonyms as alternatives.

\section{Discussion}

\subsection{Factor Analysis of FLRAS and FLRSUS}

Rotated principal factor analyses showed that FLWAS had 3 important factors: Low Self-Confidence in Writing English (FLWAS1), Dislike of Writing English (FLWAS2), and English Writing Evaluation Apprehension (FLWAS3), consistent with the finding in Cheng et al. (1999). Since the FLWAS was basically the same as SEWAS used in Cheng et al. (1999), the three factors were generally named after those in Cheng et al. (1999). And the finding of the present study further proves that foreign language writing anxiety is specific and concrete, as found in Cheng et al. (1999).

Even so, the construct validity and components of FLWAS need to be future researched. Only when they are consistently confirmed will data from samples in different FL/SL contexts be better analyzed and compared in terms of FL writing anxiety to better understand the issue. It will also enable us to better examine the relations between foreign language writing anxiety and other language learning-related variables such as past experiences, self-confidence, and self-efficacy, as found in the current literature (Cheng, 2002; Faigley et al., 1981; Kean et 
al., 1987; Woodrow, 2011; Yan \& Wang, 2014).

\subsection{Profiles of the Students' FL Writing Anxiety}

Statistical analyses showed that more than half of the students were confident in (FLWAS1) and liked (FLWAS2) English writing, were not afraid of having their English writing evaluated (FLWAS3), and were not anxious about English writing (FLWAS), consistent with findings about general foreign language classroom anxiety (Liu, 2006, 2009; Lu \& Liu, 2011; Shao et al., 2013) and other types of anxiety (Liu \& Hu, 2009; Wu, 2011) in Chinese EFL contexts. And it was the same with male and female students. This might be because writing, though often the most challenging part of SL learning, is not so indispensible as the other three skills (i.e., reading, listening and speaking), and accounts for a small portion of scores in English examinations. For example, writing accounts for $0-10$ out of the total 120 scores in the National Matriculation English Examination, the most important English examination for high school graduates, and 15 out of the total 100 scores in College English Test bands 4 and 6, the most important proficiency and exit English tests for undergraduate and postgraduate non-English majors respectively in China.

Even so, around one third of the respondents did report experiencing anxiety when writing in English, and interview participants reported greater FL writing anxiety. This indicates that FL writing anxiety is as complex as FL anxiety and needs continuous research in various SL/FL contexts. This also demonstrates that help is needed, especially by learners with high FL writing anxiety. It is necessary for both language instructors and learners to be aware of the existence of writing anxiety and take strategies accordingly to help anxious learners to writer better in a SL/FL.

Independent samples t-tests displayed that compared with their female counterparts, the male students felt significantly more anxious about English writing (FLWAS), significantly less confident in English writing (FLWAS1), and significantly more apprehensive of English writing evaluation (FLWAS3), and liked English writing significantly less (FLWAS2), different from what was found in Cheng (2002). This might be related to the number of male and female participants in the two studies, which deserves further research. To better understand gender difference in foreign language writing anxiety, future research can also focus on whether and why male and female EFL learners feel differently when writing in English.

Statistical analyses also revealed that the three proficiency groups differed significantly from one another in terms of confidence in English writing (FLWAS1) and overall English writing anxiety (FLWAS), and that the low-proficiency group differed from their group 2 and 3 peers in dislike of English writing (FLWAS2) and their group 3 counterparts in English writing evaluation apprehension (FLWAS3). Alternatively, the more proficient in English writing a student was, the more confident s/he was in English writing, the more s/he liked English writing and the less s/he was afraid of having his/her English writing evaluated. This supports Cheng's (2002) finding that foreign language writing competence was an important factor in foreign language writing anxiety.

\subsection{Effect of and Causes for FL Writing Anxiety}

Correlational and regressional analyses indicated that English writing anxiety was significantly negatively related to students' English writing performance, and that low confidence in English writing was a powerful negative predictor for the latter, as found in the current literature (Cheng, 2002; Faigley et al., 1981; Kean et al., 1987; Woodrow, 2011; Yan \& Wang, 2014). Nevertheless, as not much research on FL writing anxiety can be located, more studies are called for to further examine the relationship between FL writing anxiety and FL writing performance, especially when other variables such as self-efficacy, FL writing competence, and time pressure may mediate the effect of FL writing anxiety, as found in the present study as well as others (Cheng, 2002, 2004; Kean et al., 1987; Woodrow, 2011; Yan \& Wang, 2014). Future research can explore how FL writing anxiety interacts with other variables to affect FL writing performance.

The present study also revealed that the students became anxious when writing in English due to a number of reasons such as the difficulty of English writing, the desire to write better, worry about exam scores, the lack of vocabulary, the lack of FL writing practice, and unfamiliarity with the writing genre. Nevertheless, whether these causes are universal or specific to the present context needs to be confirmed with other FL learners in other FL contexts. With a better understanding of what causes learners to become anxious when writing in a SL/FL, it will be better to language instructors and learners to employ strategies to cope with the anxiety accordingly.

\section{Conclusion}

The present research explored FL writing anxiety in Chinese undergraduate learners in terms of pattern, effect and causes, which yielded the following results:

1) Factor analyses showed that FLWAS has 3 important factors: Low Self-Confidence in Writing English 
(FLWAS1), Dislike of Writing English (FLWAS2), and English Writing Evaluation Apprehension (FLWAS3).

2) More than half of the students were confident in (FLWAS1) and liked (FLWAS2) English writing, were not afraid of having their English writing evaluated (FLWAS3), and were not anxious about English writing (FLWAS). And it was the same with male and female students.

3) Compared with their female counterparts, the male students felt significantly more anxious about English writing (FLWAS), significantly less confident in English writing (FLWAS1), significantly more apprehensive of English writing evaluation (FLWAS3), and liked English writing significantly less (FLWAS2).

4) The three proficiency groups differed significantly from one another in terms of confidence in English writing (FLWAS1) and overall English writing anxiety (FLWAS), the low-proficiency group differed from their group 2 and 3 peers in dislike of English writing (FLWAS2) and their group 3 counterparts in English writing evaluation apprehension (FLWAS3).

5) English writing anxiety was significantly negatively related to students' English writing performance, and low confidence in English writing (FLWAS1) proved to be a powerful negative predictor for the latter.

6) A number of factors were identified by the students to cause foreign language writing anxiety. In order to cope with the anxiety, different strategies were adopted by the students.

\section{Acknowledgement}

The present study was sponsored by the 2014-2015 SRT project titled "Foreign Language Writing Anxiety", Tsinghua University.

\section{References}

Aida, Y. (1994). Examination of Horwitz, Horwitz, and Cope's construct of foreign language anxiety: The case of students of Japanese. The Modern Language Journal, 78, 155-168.

Barratt, E. S. (1972). Anxiety and impulsiveness: toward a neuropsychological model. In C. D. Speilberger (Ed.), Anxiety: current trends in theory and research (Vol. 1., pp. 195-222). New York: Academic Press.

Cheng, Y.-S. (2002). Factors associated with foreign language writing anxiety. Foreign Language Annals, 35, 647-656.

Cheng, Y.-S. (2004). A measure of second writing anxiety: Scale development and preliminary validation. Journal of Second Language Writing, 13, 313-335.

Cheng, Y.-S., Horwitz, E. K., \& Schallert, D. L. (1999). Language anxiety: Differentiating writing and speaking components. Language Learning, 49(3), 417-446.

Chu, H.-N. (2008). Shyness and EFL learning in Taiwan: A study of shy and non-shy college students' use of strategies, foreign language anxiety, motivation and willingness to communicate (Unpublished Ph.D dissertation). The University of Texas at Austin.

Coulombe, D. (2000). Anxiety and beliefs of French-as-a-second language learners at the university level (Unpublished doctoral dissertation). University of Laval, Québec, Canada.

Daly, J. A., \& Miller, M. D. (1975). The empirical development of an instrument of writing apprehension. Research in the Teaching of English, 9, 242-249.

Dewaele, J. M., \& MacIntyre, P. D. (2014). The two faces of Janus? Anxiety and enjoyment in the foreign language classroom. Studies in Second Language Learning and Teaching, 4(2), 237-274.

Dewaele, J. M., \& Thirtle, H. (2009). Why do some young learners drop Foreign Languages? A focus on learner-internal variables. International Journal of Bilingual Education and Bilingualism, 12, 635-649.

Dewaele, J. M., \& Tsui, T. (2013). The link between foreign language classroom anxiety, second language tolerance of ambiguity and self-rated English proficiency among Chinese learners. Studies in Second Language Learning and Teaching, 3(1), 47-66.

Ewald, J. D. (2007). Foreign language learning anxiety in upper-level classes: Involving students as researchers. Foreign Language Annals, 40(1), 122-141.

Faigley, L., Daly, J. A., \& Witte, S. P. (1981). The role of writing apprehension in writing performance and competence. Journal of Educational Research, 75, 16-21.

Gregersen, T., Meza, M. D., \& MacIntyre, P. D. (2014). The motion of emotion: Idiodynamic case studies of learner's foreign language anxiety. The Modern Language Journal, 98(2), 574-588. 
Gungle, B. W., \& Taylor, V. (1989). Writing apprehension and second language writers. In D. M. Johnson, \& D. H. Roen (Eds.), Richness in writing: Empowering ESL students. New York: Longman.

Horwitz, E. K. (2000). It ain't over 'til it's over: On foreign language anxiety, first language deficits, and the confounding of variables. Modern Language Journal, 84, 256-259.

Horwitz, E. K. (2001). Language anxiety and achievement. Annual Review of Applied Linguistics, 21, 112-126.

Horwitz, E. K., Horwitz, M. B., \& Cope, J. A. (1986). Foreign language classroom anxiety. Modern Language Journal, 70, 125-132.

Hurd, S., \& Xiao, J. (2010). Anxiety and affective control among sistance language learners in China and the UK. RELC Journal, 41(2), 183-200.

Kean, D., Gylnn, S., \& Britton, B. (1987). Writing persuasive documents: The role of students' verbal aptitude and evaluation anxiety. Journal of Experimental Education, 55, 95-102.

Kim, J. H. (2000). Foreign language listening anxiety: A study of Korean students learning English (Unpublished doctoral dissertation). The University of Texas, Austin.

Kitano, K. (2001). Anxiety in the college Japanese language classroom. The Modern Language Journal, 85, $549-566$.

Leki, I. (1999). Techniques for reducing second language writing anxiety. In D. J. Young (Ed.), Affect in foreign language and second language learning: A practical guide to creating a low-anxiety classroom atmosphere (pp. 64-88). Boston: McGraw-Hill.

Liu, M. (2006). Anxiety in Chinese EFL students at different proficiency levels. System, 34(3), 301-316.

Liu, M. (2009). Reticence and anxiety in oral English lessons. Bern: Peter Lang.

Liu, M., \& Hu, Y. (2009). Reading anxiety in EFL classrooms: A case study. Proceedings of the $3^{\text {rd }}$ International Symposium on Teaching English at Tertiary level (pp. 48-56). Hong Kong: Hong Kong Polytechnic University.

Liu, M., \& Jackson, J. (2008). An exploration of Chinese EFL Learners' unwillingness to communicate and foreign language anxiety. The Modern Language Journal, 92(1), 71-86.

Lu, S. H. (2005). A correlation study of computer anxiety, second language writing apprehension, and Taiwanese college student experiences with word processing (Unpublished doctoral dissertation). The University of Mississippi, Oxford.

Lu, Z., \& Liu, M. (2011). Foreign language anxiety and strategy use: A study with Chinese undergraduate EFL learners. Journal of Language Teaching and Research, 2(6), 1298-1305.

Machida, S. (2001). Anxiety in Japanese-language classroom. Modern Language Journal, 85(4), 549-566.

MacIntyre, P. D., \& Gardner, R. C. (1989). Anxiety and second-language learning: Toward a theoretical clarification. Language Learning, 39, 251-275.

MacIntyre, P. D., Baker, S. C., Clément, R., \& Donovan, L. A. (2003). Sex and age effects on willingness to communicate, anxiety, perceived competence, and L2 motivation among junior high school French immersion students. Language Learning, 53(1), 137-165.

Marcos-Llinás, M., \& Garau, M. J. (2009). Effects of language anxiety on three proficiency-level courses of Spanish as a foreign language. Foreign Language Annals, 42, 94-111.

Matsuda, S., \& Gobel, P. (2004). Anxiety and predictors of performance in the foreign language classroom. System, 32, 21-36.

Mejías, H., Applbaum, R. L., \& Trotter, R. T. (1991). Oral communication apprehension and Hispanics: An exploration of oral communication apprehension among Mexican American students in Texas. In E. K. Horwitz, \& D. J. Young (Eds.), Language anxiety: From theory and research to classroom implications (pp. 87-97). Englewood Cliffs, NJ: Prentice-Hall.

Mills, N., Pajares, F., \& Herron, C. (2006). A reevaluation of the role of anxiety: Self-efficacy, anxiety, and their relation to reading and listening proficiency. Foreign Language Annals, 39(2), 276-295.

Peterson, C., Engle, L., Kenney, L., Kreutzer, K., Nolting, W., \& Ogden, A. (2007). Defining terms for use in designing outcomes assessment projects. In M. Bolen (Ed.), A Guide to Outcomes Assessment in Education Abroad (pp. 163-204). Carlisle, PA, USA: Forum on Education Abroad. 
Pichette, F. (2009). Second language anxiety and distance language learning. Foreign Language Annals, 42(1), 77-93.

Rachman, S. (1998). Anxiety. Hove, East Sussex, UK: Psychology Press.

Shao, K., Ji, Z., \& Yu, W. (2013). An exploration of Chinese EFL students' emotional intelligence and foreign language anxiety. The Modern Language Journal, 97(4), 917-929.

Spielberger, C. D. (Ed.). (1972). Anxiety: Current trends in theory and research (Vol. 1). New York: Academic Press.

Tallon, M. (2009). Foreign language anxiety and heritage students of Spanish: A quantitative study. Foreign Language Annals, 42(1), 112-137.

Vogely, A. J. (1998). Listening comprehension anxiety: Students' reported sources and solutions. Foreign Language Annals, 31, 67-80.

Woodrow, L. J. (2006). Anxiety and speaking English as a second language. RELC Journal, 27(3), 308-328.

Woodrow, L. J. (2011). College English writing effect: Self-efficacy and anxiety. System, 39, 510-522.

$\mathrm{Wu}, \mathrm{H}$. J. (2011). Anxiety and reading comprehension performance in English as a foreign language. Asian EFL Journal, 13(2), 273-306.

Yan, J. X., \& Wang, H. (2012). Second language writing anxiety and translation. The Interpreter and Translator Trainer, 6(2), 171-194.

Young, D. J. (1999). Foreign Language Writing Anxiety Scale (FLWAS). In D. J. Young (Ed.), Affect in foreign language and second language learning: A practical guide to creating a low-anxiety classroom atmosphere (p. 257). New York: McGraw Hill.

\section{Copyrights}

Copyright for this article is retained by the author(s), with first publication rights granted to the journal.

This is an open-access article distributed under the terms and conditions of the Creative Commons Attribution license (http://creativecommons.org/licenses/by/3.0/). 